\title{
Comparison of Acetate-butyrate and Acetate-ethanol Metabolic Pathway in Biohydrogen Production
}

\begin{abstract}
Background: Hydrogen gas is the cleanest energy carrier and could be produced by biological process. Dark fermentation is one of the biohydrogen production methods that carried out just on organic wastes conversion. Methods: In this study, the batch tests were conducted to compare the biohydrogen production and glucose fermentation via acetate-butyrate and acetate-ethanol metabolic pathway induced by $\mathrm{NaOH}$ and $\mathrm{KOH}(10 \mathrm{M})$ pretreatment. In batch test, the glucose concentration in the feed was varied from 3.75 to $15 \mathrm{~g} / \mathrm{L}$ under mesophilic conditions $\left(37^{\circ} \mathrm{C} \pm 1{ }^{\circ} \mathrm{C}\right)$. In order to sludge pretreatment, $\mathrm{NaOH}$ and $\mathrm{KOH}$ (as an alkaline agent) was used. Results: Batch tests showed that maximum biohydrogen production under $\mathrm{NaOH}(2.7 \pm 0.5 \mathrm{~L})$ and $\mathrm{KOH}(2.2 \pm 0.7 \mathrm{~L})$ pretreatment was achieved at $15 \mathrm{~g} / \mathrm{L}$ of influent glucose. In the batch test, with increasing influent glucose concentration, the lower yields of hydrogen were observed. The biohydrogen reactions had good electron closure $(5.2 \%-13.5 \%)$ for various glucose concentrations and pretreatments. For $\mathrm{NaOH}$ and $\mathrm{KOH}$ pretreatment, the biohydrogen yield decreased from 2.49 to 1.63 and from 2.22 to $1.2 \mathrm{~mol} \mathrm{H}_{2} / \mathrm{mol}$ glucose, respectively, when glucose concentration increased from 3.75 to $15 \mathrm{~g} / \mathrm{L}$. Conclusions: By applying alkaline sludge pretreatment by $\mathrm{NaOH}$ and $\mathrm{KOH}$, the glucose fermentation was followed with acetate-butyrate and acetate-ethanol metabolic pathway, respectively. The lower biohydrogen yields were observed under acetate-ethanol metabolic pathway and related to metabolically unfavorable for biohydrogen production.
\end{abstract}

Keywords: Acetate-butyrate pathway, acetate-ethanol metabolic, biohydrogen production

\section{Introduction}

The concerns of environmental issues have proven hydrogen as an alternative fuel because of its nonpolluting features. ${ }^{[1,2]}$ Biohydrogen production is possible by nonbiological and biological methods. The biological method for hydrogen production includes direct photobiological production, indirect photobiological production, photo fermentation, and dark fermentation. ${ }^{[3]}$

Dark fermentation is one of the biohydrogen production methods that carried out independently on fuel energy and just on organic wastes conversion. In using the sludge as a mix culture for biohydrogen production, pretreatment is necessary for deactivation of methane-producing bacteria. Different methods such as acid, base, heating, using chemical compound, aeration, and ultrasonication were used as a pretreatment for enriching biohydrogen-producing bacteria. ${ }^{[4-7]}$

The method that was used for sludge pretreatment is an effective factor in

This is an open access journal, and articles are distributed under the terms of the Creative Commons Attribution-NonCommercialShareAlike 4.0 License, which allows others to remix, tweak, and build upon the work non-commercially, as long as appropriate credit is given and the new creations are licensed under the identical terms.

For reprints contact: reprints@medknow.com the dominance of special pathway for biohydrogen production, for example, by heating sludge as a pretreatment method can select spore-forming bacteria such as clostridia or pretreatment by aeration led to Clostridium sp. and Enterobacter dominance. ${ }^{[6,8]}$ The efficiency of biohydrogen production process is different depending on pretreatment method, dominance bacteria, substrate, and metabolic pathway. ${ }^{[9,10]}$ With understanding metabolic pathway, the calculation of theoretical hydrogen yield is possible. ${ }^{[1]}$

The main introduced pathways for hydrogen production in dark fermentation are acetate-butyrate and acetate-ethanol pathway. ${ }^{[2,12]}$ Acetate-propionate pathway is another fermentation pathway that does not produce any hydrogen. ${ }^{[8]}$

Acetate-butyrate metabolic has been reported in many studies as a dominant pathway for hydrogen production that has been down by butyrate type fermentation bacteria such as Clostridium, Butyrivibrio, and Bacillus, but this pathway can

How to cite this article: Taheri E, Amin MM,
Pourzamani H, Fatehizadeh A, Ghasemian M, Bina B.
Comparison of acetate-butyrate and acetate-ethanol
metabolic pathway in biohydrogen production. J Med
Sign Sens 2018;8:101-7.

\section{Ensiyeh Taheri ${ }^{1,2}$, Mohammad Mehdi Amin ${ }^{1,2}$, Hamidreza \\ Pourzamani ${ }^{1,3}$, Ali Fatehizadeh ${ }^{1,3}$, Mohammad Ghasemian ${ }^{1,3}$, Bijan Bina ${ }^{1,3}$}

${ }^{I}$ Department of Environmental Health Engineering, School of Health, Isfahan University of Medical Sciences, ${ }^{2}$ Student Research Committee, School of Health, Isfahan University of Medical Sciences,

${ }^{3}$ Environment Research Center, Research Institute for Primordial Prevention of Non-Communicable Disease, Isfahan University of Medical Sciences, Isfahan, Iran
Address for correspondence: Dr. Bijan Bina,

Department of Environmental Health Engineering, School of Health, Isfahan University of Medical Sciences, Isfahan, Iran. E-mail: bbina123@yhaoo.com

Website: www.jmss.mui.ac.ir DOI: 10.4103/jmss.JMSS_6_18 
convert to butanol production way that is the hydrogen consumption pathway. In comparison to acetate-butyrate metabolic pathway, acetate-ethanol pathway is more stable way for hydrogen production and it seems that this pathway has been down by Ethanoligenens, Acetanaerobacterium, Clostridum, Rhodopseudomona, and Citrobacter (the dominant genera are unknown). ${ }^{[8,12]}$

Different pretreatment methods lead to the domination of different bacterial communities in biohydrogen production and can face with different metabolic pathways. Production of various components in each metabolic pathway shows the different distributions of electron equivalents. Hence, in this study, biohydrogen production via acetate-butyrate and acetate-ethanol pathway induced by sludge pretreatment was studied and also biohydrogen production stoichiometry was carried out. In addition, for better understanding of the microbial metabolism, the mass balance recovery was down.

\section{Materials and Methods}

\section{Enriching of biohydrogen-producing inoculum}

The parent anaerobic digested sludge was extracted from a full-scale municipal sludge digester (South Municipal Wastewater Treatment Plant, Tehran, Iran). The properties of parent anaerobic sludge are summarized in Table 1. According to Amin et al.'s study, this anaerobic sludge showed good biohydrogen production potential. ${ }^{[9]}$ Before alkaline pretreatment, the sludge was sifting by a standard sieve \#16 with $1.19 \mathrm{~mm}$ pore size. Two different alkaline

\begin{tabular}{lcc}
\hline \multicolumn{2}{c}{ Table 1: Properties of parent anaerobic sludge } \\
\hline Parameter & Unit & Value \\
\hline pH & - & $7.75 \pm 0.1$ \\
Soluble COD & g/L & $2.5 \pm 0.4$ \\
Total COD & g/L & $12.6 \pm 2.2$ \\
VSS & g/L & $16.84 \pm 3.4$ \\
And TSS & g/L & $32.56 \pm 6.6$ \\
\hline
\end{tabular}

COD - Chemical oxygen demand; VSS - Volatile suspended solid; TSS - Total suspended solid pretreatment agents were evaluated and are including $\mathrm{NaOH}$ and $\mathrm{KOH}$ agents (10 $\mathrm{M}$ solution). In order to biohydrogen-producing bacteria enrichment, the solution $\mathrm{pH}$ of anaerobic sludge was increased to 12 using each alkaline agent individually under anaerobic environment for $24 \mathrm{~h}$ and then sludge $\mathrm{pH}$ adjusted to 7 by $\mathrm{HCl}^{\left[{ }^{[13]}\right.}$

\section{Batch test procedure}

The batch tests were carried out in $500 \mathrm{~mL}$ glass bottles that contain $200 \mathrm{~mL}$ feed solution and $200 \mathrm{~mL}$ of pretreated sludge as demonstrated by Amin et al.'s study. ${ }^{[9]}$ Glucose was used as sole carbon source at influent concentration of $3.75,7.5,11.25$, and $15 \mathrm{~g} / \mathrm{L}$ that is equal to $0.5,1$, 1.5 , and 2 electron equivalents ( $\left.\mathrm{e}^{-} \mathrm{eq}\right)$, respectively. The details of medium composition are described in Amin et al.'s study. ${ }^{[14]}$ The batch tests were done in duplicate and incubated at $37^{\circ} \mathrm{C} \pm 1{ }^{\circ} \mathrm{C}$ and stirred glass flasks (360 s idle and $30 \mathrm{~s}$ mixing) for $48 \mathrm{~h}$. Before incubation, for insurance of anaerobic condition and sludge and substrate contact, each vial was purged by $\mathrm{N}_{2}$ gas for $3 \mathrm{~min}(400 \mathrm{~mL} / \mathrm{min})$.

\section{Analytical methods}

The fermentation metabolites including volatile fatty acids (VFAs) such as acetic, propionic, butyric, and valeric acid and solvents including methanol, ethanol, and acetone were analyzed by a flame ionization detector (GC-FID, Agilent 7890A GC with Varian CP-Sil5cb column) as described in the literature. ${ }^{[15,16]}$ The chromatographic program was as follows: the helium gas at flow rate of $1 \mathrm{~mL} / \mathrm{min}(19.086 \mathrm{~cm} / \mathrm{s})$ was used as a carrier gas; oven temperature was $70^{\circ} \mathrm{C}(3 \mathrm{~min})$, first ramp as $10^{\circ} \mathrm{C} / \mathrm{min}$ to $130^{\circ} \mathrm{C}(0 \mathrm{~min})$, second $\mathrm{ramp}$ as $5^{\circ} \mathrm{C} / \mathrm{min}$ to $180^{\circ} \mathrm{C}(5 \mathrm{~min})$, and post run $250^{\circ} \mathrm{C}(1 \mathrm{~min})$. The nitrogen gas was used as a makeup at flow rate of $30 \mathrm{~mL} / \mathrm{min}$. The standard curve of VFAs and solvent is shown in Figure 1. Other test methods including solution $\mathrm{pH}$, alkalinity, COD, and glucose residual were measured using a glass body $\mathrm{pH}$ probe (CG 824 SCHOTT), titration method, closed reflux, colorimetric method, and phenol-sulfuric acid methods according to Amin et al.'s study. ${ }^{[9]}$
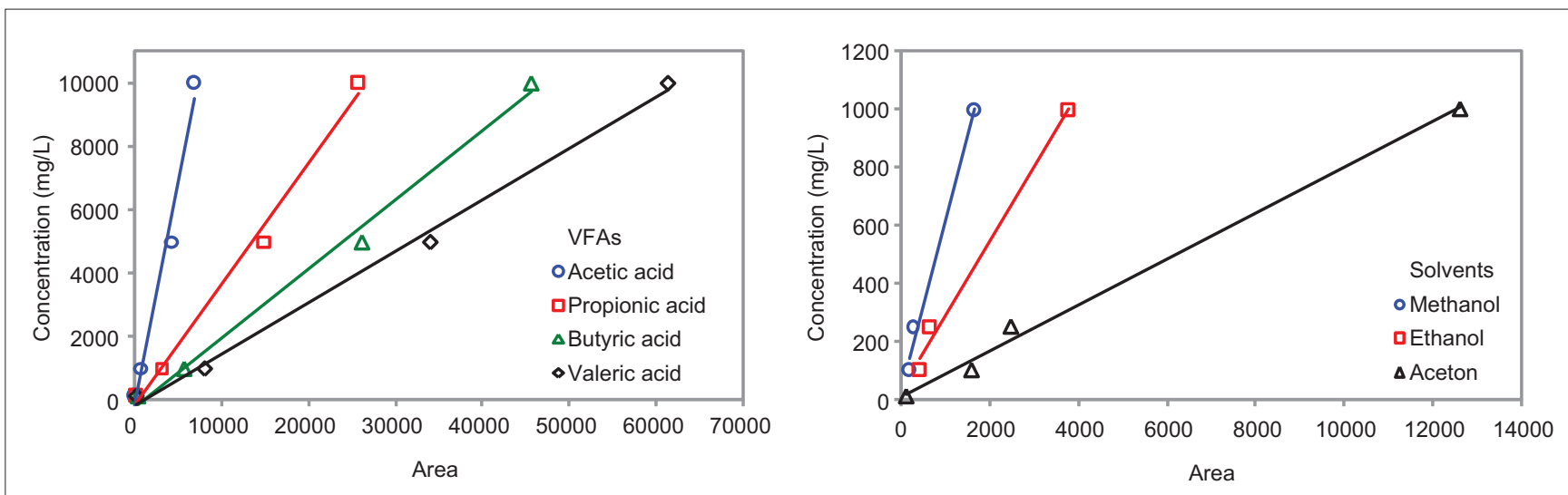

Figure 1: Volatile fatty acids and solvent standard curve 


\section{Calculation}

For establishing the mass balance recovery based on the $\mathrm{e}^{-}$eq in the batch tests, Eq. 1 was used as proposed in previous literature. ${ }^{[17,18]}$

$e_{\mathrm{glu}, \mathrm{in}}^{-}=e_{\mathrm{SEP}}^{-}+e_{\mathrm{H}_{2}}^{-}+e_{\text {biomass }}^{-}+e_{\mathrm{glu}, \mathrm{eff}}^{-}$

Where $\mathrm{e}^{-}$glu, in is $\mathrm{e}^{-}$eq of influent glucose, $\mathrm{e}_{\text {SEP }}^{-}$is $\mathrm{e}^{-}$eq of soluble end products, $e_{\mathrm{H}_{2}}^{-}$is $\mathrm{e}^{-}$eq of biohydrogen during incubation period, $\mathrm{e}^{-}$biomass is $\mathrm{e}^{-}$eq of biomass growth, and $\mathrm{e}_{\text {glu,eff }}^{-}$is the $\mathrm{e}^{-}$eq of residual glucose after incubation. The SEPs include acetate, propionate, butyrate, formate, lactate, acetone, methanol, and ethanol. The conversion of $\mathrm{e}^{-}$eq measured value was done based on this fact $1 \mathrm{e}^{-}$eq is equal to $7.5 \mathrm{~g}$ of glucose, $7.38 \mathrm{~g}$ of acetate, $5.22 \mathrm{~g}$ of propionate, $4.35 \mathrm{~g}$ of butyrate, $22.65 \mathrm{~g}$ of formate, $7.42 \mathrm{~g}$ of lactate, $5.34 \mathrm{~g}$ of methanol, $3.84 \mathrm{~g}$ of ethanol, and $5.46 \mathrm{~g}$ of biomass. ${ }^{[19]}$

\section{Results}

As shown in Figure 2, in case of $\mathrm{KOH}$ pretreatment, the biohydrogen production was $0.15 \pm 0.05 \mathrm{~L}, 0.65 \pm 0.12 \mathrm{~L}$,

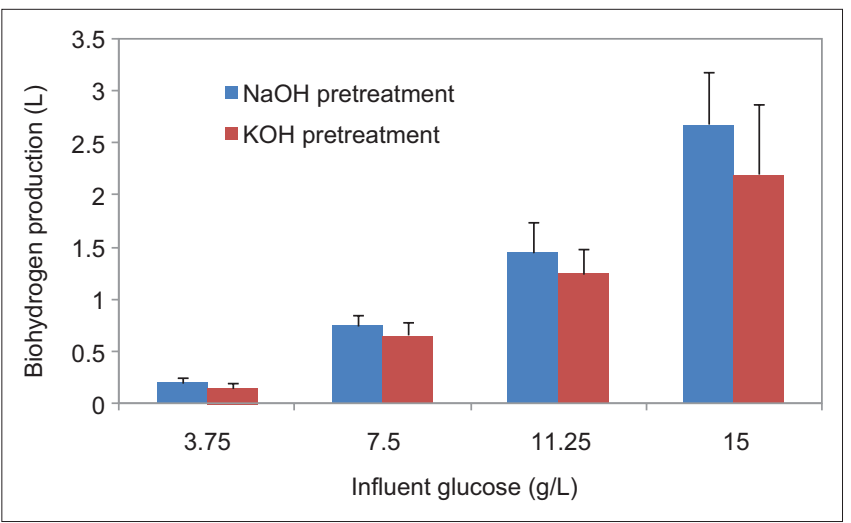

Figure 2: Average biohydrogen production during batch tests
$1.2 \pm 0.2 \mathrm{~L}$, and $2.2 \pm 0.7 \mathrm{~L}$ for $3.75,7.5,11.25$, and $15 \mathrm{~g} / \mathrm{L}$ of influent glucose, respectively. Compared with the $\mathrm{KOH}$ pretreatment, as the $\mathrm{NaOH}$ was used as pretreatment agent, the biohydrogen production was enhanced to $0.2 \pm 0.05 \mathrm{~L}$, $0.75 \pm 0.1 \mathrm{~L}, 1.5 \pm 0.3 \mathrm{~L}$, and $2.7 \pm 0.5 \mathrm{~L}$ for $3.75,7.5$, 11.25 , and $15 \mathrm{~g} / \mathrm{L}$ of influent glucose, respectively.

The glucose conversion efficiency during biohydrogen production with $\mathrm{NaOH}$ and $\mathrm{KOH}$ pretreatment of anaerobic sludge is depicted in Figure 3.

At glucose concentration of $3.75,7.5,11.25$, and $15 \mathrm{~g} / \mathrm{L}$, the glucose conversion was $90.7 \% \pm 0.05 \%, 94.1 \% \pm 0.1 \%$, $93 \pm 0.3$, and $96 \% \pm 0.5 \%$ for $\mathrm{NaOH}$ pretreatment and also $89.7 \% \pm 0.05 \%, 92.9 \% \pm 0.1 \%, 93.8 \% \pm 0.2 \%$, and $93.5 \% \pm 0.6 \%$ for $\mathrm{KOH}$ pretreatment, respectively.

Tables 2 and 3 summarize the fractions of electron acceptor at different glucose concentrations under $\mathrm{NaOH}$ and $\mathrm{KOH}$ sludge pretreatment. As depicted in Tables 2 and 3, the dominate electron acceptors under $\mathrm{NaOH}$ and $\mathrm{KOH}$ pretreatment were acetate and butyrate and also ethanol and acetate, respectively.

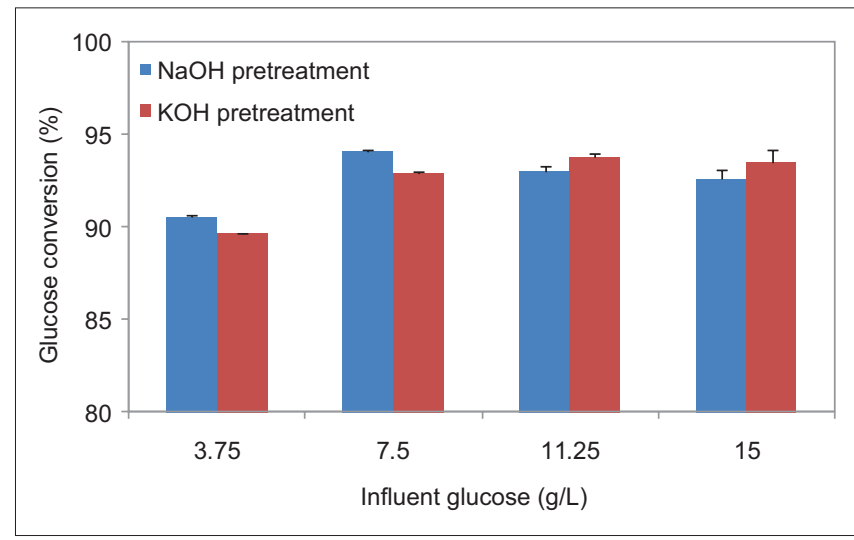

Figure 3: Glucose conversion during biohydrogen production

\begin{tabular}{lcccc}
\hline & \multicolumn{4}{c}{ Table 2: Fractions of electron acceptor under NaOH sludge pretreatment } \\
\hline & \multicolumn{4}{c}{ Glucose concentration } \\
\cline { 2 - 5 } Compounds & $\mathbf{3 . 7 5}(\mathbf{g} / \mathbf{L}) \mathbf{( \% )}$ & $\mathbf{7 . 5}(\mathbf{g} / \mathbf{L})(\mathbf{\%})$ & $\mathbf{1 1 . 2 5}(\mathbf{g} / \mathbf{L}) \mathbf{( \% )}$ & $\mathbf{1 5}(\mathbf{g} / \mathbf{L}) \mathbf{( \% )}$ \\
\hline Glucose influent & $200(100)$ & $400(100)$ & $600(100)$ & $800(100)$ \\
Acetate & $74.3 \pm 2.1(40.1)$ & $140.3 \pm 8.1(36.3)$ & $194.5 \pm 7.7(34.5)$ & $248.7 \pm 11.1(33.6)$ \\
Propionate & $1.8 \pm 3.1(1.1)$ & $9.4 \pm 1.1(2.4)$ & $9.9 \pm 2.1(1.7)$ & $9 \pm 1.8(1.3)$ \\
Butyrate & $57.8 \pm 3.1(31.2)$ & $101.7 \pm 5.1(26.3)$ & $193.5 \pm 5.1(34.3)$ & $230.3 \pm 10.1(31.1)$ \\
Formate & $\mathrm{ND}$ & $\mathrm{ND}$ & $\mathrm{ND}$ & $\mathrm{ND}$ \\
Lactate & $\mathrm{ND}$ & $\mathrm{ND}$ & $\mathrm{ND}$ & $\mathrm{ND}$ \\
Acetone & $\mathrm{ND}$ & $\mathrm{ND}$ & $\mathrm{ND}$ & $\mathrm{ND}$ \\
Methanol & $\mathrm{ND}$ & $\mathrm{ND}$ & $\mathrm{ND}$ & $\mathrm{ND}$ \\
Ethanol & $\mathrm{ND}$ & $56.7 \pm 2.3(14.6)$ & $27.7 \pm 4.5(4.9)$ & $\mathrm{ND}$ \\
Biomass & $16.9 \pm 1.9(9.1)$ & $25.4 \pm 5.4(6.6)$ & $42.0 \pm 10.1(7.4)$ & $27.7 \pm 3.2(3.7)$ \\
Residual glucose & $18.9 \pm 8.9(10.2)$ & $53.4 \pm 6.8(13.8)$ & $97.3 \pm 11.1(17.2)$ & $42.0 \pm 9.8(5.7)$ \\
Biohydrogen & $15.7 \pm 4.9(8.4)$ & 387.1 & 564.6 & $182 \pm 13.1(24.6)$ \\
Total & 182.5 & 3.1 & 5.8 & 740.7 \\
$\Delta \mathrm{e}^{-}$eq $(\%)$ & 8.7 & & 7.3 \\
\hline
\end{tabular}

${ }^{*}$ Units are in $\mathrm{e}^{-}$eq $(\%)$. $\mathrm{e}^{-}$eq - Electron equivalent; ND - Non Detectable 
The final form of stoichiometric reactions of biohydrogen production under $\mathrm{NaOH}$ and $\mathrm{KOH}$ pretreatment as function of influent glucose concentration is shown in Table 4.

\section{Discussion}

Biohydrogen production and glucose conversion

Overall, the analysis of produced biogas was depicted that biogas contains $40 \%-44 \%$ of hydrogen and no methane was detected, which demonstrated efficient inactivation of methanogens bacteria during sludge pretreatment. The amounts of biohydrogen production during batch tests are shown in Figure 2. As shown in Figure 2, in overall, with increasing influent glucose concentration, the amount of biohydrogen production increased, suggesting that the glucose concentration had a great effect on biohydrogen production. The highest biohydrogen production was obtained at $15 \mathrm{~g} / \mathrm{L}$ of influent glucose concentration with respect to $2.6 \pm 0.5 \mathrm{~L}$ and $2.2 \pm 0.7 \mathrm{~L}$ for $\mathrm{NaOH}$ and $\mathrm{KOH}$ pretreatment, respectively.

The obtained results are in line with previous study. According to the report by Van Ginkel et al., with increasing influent COD from 0.5 to $20 \mathrm{~g} / \mathrm{L}$, the biohydrogen production increases from 0.1 to $2.8 \mathrm{~L} .{ }^{[20]}$
Overall, the glucose conversion efficiency during batch test was high and glucose conversion was more than $90 \%$. With application of $\mathrm{KOH}$ as a pretreatment agent, the glucose conversion was slightly lower than $\mathrm{NaOH}$ pretreatment and related to dominant biohydrogen production bacteria. The glucose conversion is responsible for complete fermentation and it has been demonstrated that the culture media are highly capable of glucose fermentation and biohydrogen production. In the previous study, Whang et al. reported $99 \%$ of the glucose consumption efficiency. ${ }^{[1]}$

End products and mass balance recovery

Depending on initial microorganisms culture and operation conditions, during carbohydrates fermentation, as the primary metabolites, several VFAs and alcohols are produced. ${ }^{[11]}$ The end products of biohydrogen production included volatile organic acids (acetic, propionic, butyric, formic, and lactic acid), alcohols (methanol, ethanol, and acetone), biomass, biohydrogen gas, and also residual glucose. The distribution of glucose fermentation products in biohydrogen batch tests conducted with the $\mathrm{NaOH}$ pretreatment based on the $\mathrm{e}^{-}$eq and percentage is summarized in Table 2.

\begin{tabular}{lcccc}
\hline & Table 3: Fractions of electron acceptor under KOH sludge pretreatment \\
\hline & \multicolumn{4}{c}{ Glucose concentration } \\
\cline { 2 - 5 } Compounds & $\mathbf{3 . 7 5}(\mathbf{g} / \mathbf{L}) \mathbf{( \% )}$ & $\mathbf{7 . 5}(\mathbf{g} / \mathbf{L}) \mathbf{( \% )}$ & $\mathbf{1 1 . 2 5}(\mathbf{g} / \mathbf{L}) \mathbf{( \% )}$ & $\mathbf{1 5}(\mathbf{g} / \mathbf{L}) \mathbf{( \% )}$ \\
\hline Glucose influent & $200(100)$ & $400(100)$ & $600(100)$ & $800(100)$ \\
Acetate & $24.4 \pm 8.1(13.5)$ & $78.6 \pm 11.1(16)$ & $138.2 \pm 21.1(24.3)$ & $165.3 \pm 18.1(22.6)$ \\
Propionate & $3.9 \pm 0.9(2.1)$ & $3.9 \pm 1.4(1)$ & $3.9 \pm 1.1(0.7)$ & $8.5 \pm 2.1(1.2)$ \\
Butyrate & $17.5 \pm 4.9(9.7)$ & $59.8 \pm 5.8(15.8)$ & $78.1 \pm 6.1(13.8)$ & $101.1 \pm 9.1(13.8)$ \\
Formate & $\mathrm{ND}$ & $\mathrm{ND}$ & $\mathrm{ND}$ & $\mathrm{ND}$ \\
Lactate & $\mathrm{ND}$ & $\mathrm{ND}$ & $\mathrm{ND}$ & $\mathrm{ND}$ \\
Acetone & $\mathrm{ND}$ & $\mathrm{ND}$ & $\mathrm{ND}$ & $\mathrm{ND}$ \\
Methanol & $\mathrm{ND}$ & $\mathrm{ND}$ & $205.1 \pm 16.1(36.1)$ & $226.1 \pm 13.1(30.8)$ \\
Ethanol & $79 \pm 12.1(43.6)$ & $121.8 \pm 12.2(32.1)$ & $6.4 \pm 2.1(1.1)$ & $7.2 \pm 3.1(1)$ \\
Biomass & $15.2 \pm 9.1(8.4)$ & $31.7 \pm 8.1(8.4)$ & $37.5 \pm 4.1(6.6)$ & $51.8 \pm 9.1(7.1)$ \\
Residual glucose & $20.7 \pm 3.1(11.4)$ & $28.3 \pm 4.8(7.5)$ & $69.1 \pm 9.1(17.3)$ & $127.2 \pm 12.1(23.6)$ \\
Biohydrogen & $12.1 \pm 6.8(11.4)$ & $54.9 \pm 10.1(14.5)$ & 567.6 & 732.6 \\
Total & 172.8 & 379 & 5.3 & 8.3 \\
$\Delta \mathrm{e}^{-}$eq $(\%)$ & 13.5 & 5.2 & & \\
\hline
\end{tabular}

*Units are in $\mathrm{e}^{-}$eq (\%). $\mathrm{e}^{-}$eq - Electron equivalent; ND - Non Detectable

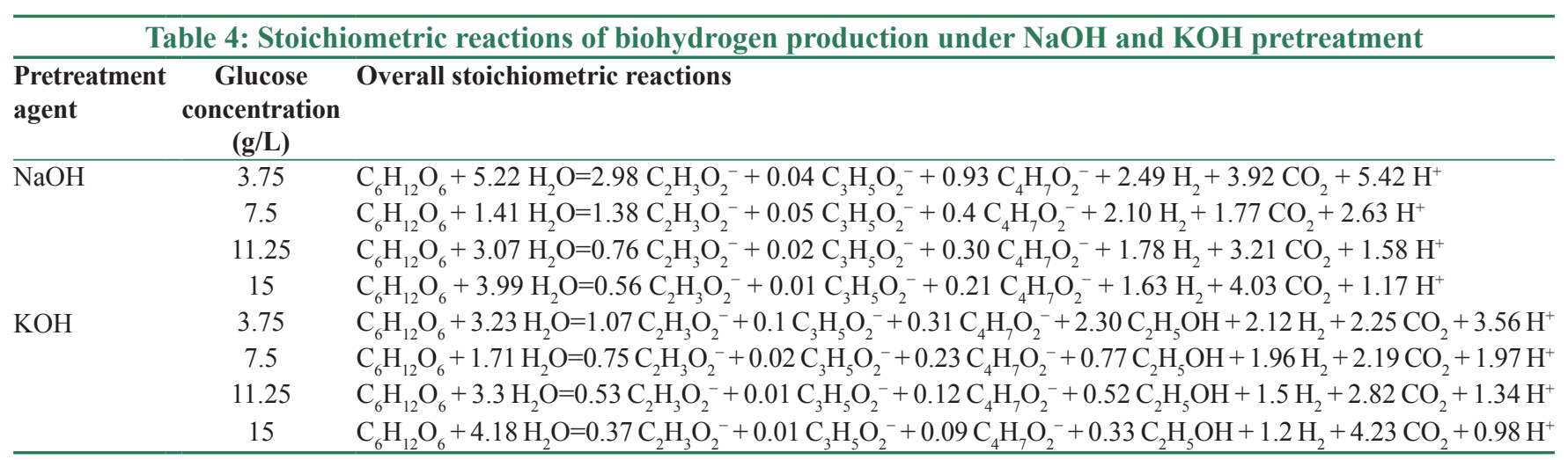


In case of $\mathrm{NaOH}$ pretreatment [Table 2], dominate soluble end products were acetate and butyrate and supported the acetate-butyrate pathway fermentation. ${ }^{[17,21]}$ The high acetate production suggested that the fermenting bacteria could efficiently conserve energy through acetate production. ${ }^{[17,22]}$ In all batch tests, the portion of biohydrogen was fluctuated from $11 \%$ to $23 \%$ and the little portion of electron sink was related to propionate $(<2 \%)$. Formate, lactate, acetone, methanol, and ethanol were not detected. In batch tests, the lactate was not observed and it has been demonstrated that the generation of molecular hydrogen by disposal mechanisms of protons and electrons is not blocked. ${ }^{[23]}$

Table 3 summarizes the end metabolites produced in batch tests with $\mathrm{KOH}$ sludge pretreatment. The amount and characteristics of soluble end products were highly related to influent glucose.

The sum of VFAs and ethanol kept increasing with influent glucose and reached to $500 \mathrm{e}^{-}$eq when influent glucose was $15 \mathrm{~g} / \mathrm{L}$ [Table 3]. Among metabolites, ethanol is a major soluble end product found in the studied influent glucose. The ethanol portion was $43.6 \%, 32.1 \%, 36.1 \%$, and $30.8 \%$ of $\mathrm{e}^{-}$eq for $3.75,7.5,11.25$, and $15 \mathrm{~g} / \mathrm{L}$ of influent glucose, respectively. The results supported our hypothesis about ethanol-based biohydrogen-producing bacteria. ${ }^{[8,24]}$

The $\mathrm{e}^{-}$eq of biohydrogen was as high as $11.4 \%, 14.5 \%$, $17.3 \%$, and $23.6 \%$ of end products for $3.75,7.5,11.25$, and $15 \mathrm{~g} / \mathrm{L}$ of influent glucose, respectively. The $\mathrm{e}^{-}$eq portion of propionate was low and ranged from $0.7 \%$ to $2.1 \%$. As the previous study demonstrated that formation of reduced ferredoxin was a critical step for biological hydrogen production, propionate, formate, and lactate accumulation had led to the hydrogen production reduction. ${ }^{[17,25]}$

For all tests, the related $\mathrm{e}^{-}$eq biomass ranged between $1 \%$ to $9.1 \%$, which was lower than those reported by Liu et al., but in the range of Lee et al. and Amin et al.'s study. ${ }^{[9,21,25]}$ These results demonstrated that actually growing of cells and adenosine triphosphate synthesis. ${ }^{[26]}$ For all batch tests, the mass balance recovery based on the $\mathrm{e}^{-}$eq were closed within $5.2 \%-13.5 \%$ and depicted good detection of end products.

The dominance component that produced by $\mathrm{NaOH}$ treated culture was butyric and acetic acid that shown the acetic-butyric pathway for hydrogen production. For $\mathrm{KOH}$ pretreated culture, the possible pathway was acetic-ethanol, because in all glucose concentrations, the major products were acetic and ethanol. It was concluded that different pretreatment methods not only have different efficiencies for methane-producing bacteria but also can choose different hydrogen production communities by various metabolic pathways. ${ }^{[13]}$

\section{Stoichiometry reaction}

The stoichiometry reaction construction was carried out according to a proposed method by Lee et al. ${ }^{[18]}$ The half-reactions for electron acceptor and donor were chosen from literature. ${ }^{[19]}$ The overall stoichiometric equations were created by adding up for all electron acceptors and donors based on the $\mathrm{e}^{-}$eq fractions in Tables 2 and 3. Table 4 summarizes the stoichiometric reactions of biohydrogen production as a function of initial glucose concentration and pretreatment agent.

As shown in Table 4, the yield of biohydrogen production was decreased with increasing influent glucose concentration for both pretreatment. In case of $\mathrm{NaOH}$ pretreatment, as the glucose concentration increased from 3.75 to $15 \mathrm{~g} / \mathrm{L}$, the biohydrogen yield decreased from 2.49 to $1.63 \mathrm{~mol} \mathrm{H}_{2} / \mathrm{mol}$ glucose. Furthermore, when $\mathrm{KOH}$ was used as a pretreatment agent, the biohydrogen yields were inversely associated with glucose concentration. Van Ginkel et al. operated two identical fermentors at different feed concentrations and reported that with decreasing the glucose loading rate from 18.9 to $0.5 \mathrm{~g}$ glucose $/ \mathrm{h}$, the yield of hydrogen production improved from 1.7 to $2.8 \mathrm{~mol} \mathrm{H}_{2} / \mathrm{mol}$ glucose. ${ }^{[20]} \mathrm{In}$ contrast, Shida et al. reported that as the organic loading increased from 19 to $140.6 \mathrm{~g}$ glucose/L/day, the biohydrogen production increased from 12 to $76 \mathrm{~L} /$ day. ${ }^{[27]}$

Overall, the acetate-butyrate pathway fermentation showed higher biohydrogen yield than acetate-ethanol pathway. When $\mathrm{KOH}$ was used as a pretreatment agent, the biohydrogen yields were $2.12,1.96,1.5$, and $1.2 \mathrm{~mol} \mathrm{H}_{2} / \mathrm{mol}$ glucose for $3.75,7.5,11.25$, and $15 \mathrm{~g} / \mathrm{L}$ of influent glucose, respectively. Compared with the $\mathrm{KOH}$, the yield of biohydrogen was enhanced by $17.5 \%, 7.1 \%, 18.7 \%$, and $35.8 \%$ for $3.75,7.5$, 11.25 , and $15 \mathrm{~g} / \mathrm{L}$ of influent glucose, respectively, during $\mathrm{NaOH}$ pretreatment (acetate-butyrate pathway).

Based on the energy conservation aspect, the acetate formation is the favor pathway for fermentor microorganisms during production from acetyl-CoA and also has led to reduced soluble end product or $\mathrm{H}_{2}$. This situation attributed to typical mesophilic fermentation types including acetate-butyrate, acetate-ethanol, and acetate-propionate. ${ }^{[17]}$ Clostridium pasteurianum is used with acetate-butyrate pathway for producing hydrogen and the highest obtained biohydrogen yield by these bacteria is $4 \mathrm{~mol} \mathrm{H}_{2} / \mathrm{mol}$ glucose. ${ }^{[20,23]}$ Conversely, the theoretical yield of hydrogen according to acetate-ethanol pathway is $2 \mathrm{~mol}$ hydrogen/mol glucose. ${ }^{[12,22]}$ The synthesis of ethanol from acetyl-CoA can produce reduced ferredoxin and also $\mathrm{H}_{2}$ generation. The lower biohydrogen production during $\mathrm{KOH}$ pretreatment presumably related to electron flows from reduced ferredoxin to $\mathrm{NAD}^{+}$and produced $\mathrm{NADH}_{2}$ instead of biohydrogen. ${ }^{[18,21]}$ The reduction of acetyl-CoA can produce ethanol and butyrate and lead to $\mathrm{NADH}_{2}$ consumption and may result in lower $\mathrm{H}_{2}$ production. ${ }^{[18]}$ 


\section{Conclusions}

This study evaluates the biohydrogen production and stoichiometry reaction of glucose fermentation by acetate-butyrate and acetate-ethanol pathway induced by sludge pretreatment. Based on the obtained results, the following conclusions can be drawn:

- The percentage of hydrogen in the biogas produced ranged from $40 \%$ to $44 \%$

- The highest biohydrogen production was obtained at $15 \mathrm{~g} / \mathrm{L}$ of influent concentration with respect to $2.6 \pm 0.5 \mathrm{~L}$ and $2.2 \pm 0.7 \mathrm{~L}$ for $\mathrm{NaOH}$ and $\mathrm{KOH}$ pretreatment, respectively

- The glucose conversion efficiency during batch test was more than $90 \%$

- For all tests, the mass balance recoveries based on the $\mathrm{e}^{-}$eq were closed within $5.2 \%-13.5 \%$

- The acetate-butyrate pathway fermentation showed higher biohydrogen yield than acetate-ethanol pathway.

\section{Acknowledgment}

The authors would like to thank the financial support of Isfahan University of Medical Sciences under project No. 394341.

\section{Financial support and sponsorship}

None.

\section{Conflicts of interest}

There are no conflicts of interest.

\section{References}

1. Liu X, Ren N, Song F, Yang C, Wang A. Recent advances in fermentative biohydrogen production. Progress Nat Sci 2008; 18:253-8.

2. Gadhe A, Sonawane SS, Varma MN. Kinetic analysis of biohydrogen production from complex dairy wastewater under optimized condition. Int J Hydrogen Energy 2014;39:1306-14.

3. Mathews J, Wang G. Metabolic pathway engineering for enhanced biohydrogen production. Int $\mathrm{J}$ Hydrogen Energy 2009;34:7404-16.

4. Zhu H, Béland M. Evaluation of alternative methods of preparing hydrogen producing seeds from digested wastewater sludge. Int J Hydrogen Energy 2006;31:1980-8.

5. Boboescu IZ, Gherman VD, Mirel I, Pap B, Tengölics R, Rákhely $\mathrm{G}$, et al. Simultaneous biohydrogen production and wastewater treatment based on the selective enrichment of the fermentation ecosystem. Int J Hydrogen Energy 2014;39:1502-10.

6. Wang J, Wan W. Comparison of different pretreatment methods for enriching hydrogen-producing bacteria from digested sludge. Int J Hydrogen Energy 2008;33:2934-41.

7. O-Thong S, Prasertsan $\mathrm{P}$, Birkeland NK. Evaluation of methods for preparing hydrogen-producing seed inocula under thermophilic condition by process performance and microbial community analysis. Bioresour Technol 2009;100:909-18.

8. Ren N, Xing D, Rittmann BE, Zhao L, Xie T, Zhao X, et al. Microbial community structure of ethanol type fermentation in bio-hydrogen production. Environ Microbiol 2007;9:1112-25.
9. Amin $\mathrm{MM}$, Bina $\mathrm{B}$, Taheri $\mathrm{E}$, Zare MR, Ghasemian $\mathrm{M}$, van Ginkel SW, et al. Metabolism and kinetic study of bioH2 production by anaerobic sludge under different acid pretreatments. Process Biochem 2017;61:24-9.

10. Amin MM, Bina B, Taheri E, Fatehizadeh A, Ghasemian M. Stoichiometry evaluation of biohydrogen production from various carbohydrates. Environ Sci Pollut Res Int 2016;23:20915-21.

11. Whang LM, Lin CA, Liu IC, Wu CW, Cheng HH. Metabolic and energetic aspects of biohydrogen production of clostridium tyrobutyricum: The effects of hydraulic retention time and peptone addition. Bioresour Technol 2011;102:8378-83.

12. Hwang MH, Jang NJ, Hyun SH, Kim IS. Anaerobic bio-hydrogen production from ethanol fermentation: The role of pH. J Biotechnol 2004;111:297-309.

13. Zhang K, Ren N, Guo C, Wang A, Cao G. Effects of various pretreatment methods on mixed microflora to enhance biohydrogen production from corn stover hydrolysate. J Environ Sci (China) 2011;23:1929-36.

14. Amin MM, Zilles JL, Greiner J, Charbonneau S, Raskin L, Morgenroth $\mathrm{E}$, et al. Influence of the antibiotic erythromycin on anaerobic treatment of a pharmaceutical wastewater. Environ Sci Technol 2006;40:3971-7.

15. Manni G, Caron F. Calibration and determination of volatile fatty acids in waste leachates by gas chromatography. J Chromatogr A 1995;690:237-42.

16. Adorno MA, Hirasawa JS, Varesche MB. Development and validation of two methods to quantify volatile acids (C2-C6) by GC/FID: Headspace (automatic and manual) and liquid-liquid extraction (LLE). Am J Anal Chem 2014;5:406.

17. Lee HS, Rittmann BE. Evaluation of metabolism using stoichiometry in fermentative biohydrogen. Biotechnol Bioeng 2009;102:749-58.

18. Lee HS, Salerno MB, Rittmann BE. Thermodynamic evaluation on $\mathrm{H} 2$ production in glucose fermentation. Environ Sci Technol 2008;42:2401-7.

19. Rittmann BE, McCarty PL. Environmental Biotechnology: Principles and Applications. New York: McGraw-Hill; 2001.

20. Van Ginkel SW, Oh SE, Logan BE. Biohydrogen gas production from food processing anddomestic wastewaters. Int J Hydrogen Energy 2005;30:1535-42.

21. Lee HS, Krajmalinik-Brown R, Zhang H, Rittmann BE. An electron-flow model can predict complex redox reactions in mixed-culture fermentative bioH2: Microbial ecology evidence. Biotechnol Bioeng 2009;104:687-97.

22. Thauer RK, Jungermann K, Decker K. Energy conservation in chemotrophic anaerobic bacteria. Bacteriol Rev 1977;41:100-80.

23. Jones DT, Woods DR. Acetone-butanol fermentation revisited. Microbiol Rev 1986;50:484-524.

24. Ren N, Li J, Li B, Wang Y, Liu S. Biohydrogen production from molasses by anaerobic fermentation with a pilot-scale bioreactor system. Int J Hydrogen Energy 2006;31:2147-57.

25. Liu IC, Whang LM, Ren WJ, Lin PY. The effect of $\mathrm{pH}$ on the production of biohydrogen by clostridia: Thermodynamic and metabolic considerations. Int J Hydrogen Energy 2011;36:439-49.

26. Adams CJ, Redmond MC, Valentine DL. Pure-culture growth of fermentative bacteria, facilitated by $\mathrm{H} 2$ removal: Bioenergetics and $\mathrm{H} 2$ production. Appl Environ Microbiol 2006;72:1079-85.

27. Shida GM, Sader LT, Cavalcante de Amorim EL, Sakamoto IK, Maintinguer SI, Saavedra NK, et al. Performance and composition of bacterial communities in anaerobic fluidized bed reactors for hydrogen production: Effects of organic loading rate and alkalinity. Int J Hydrogen Energy 2012;37:16925-34. 


\section{BIOGRAPHIES}

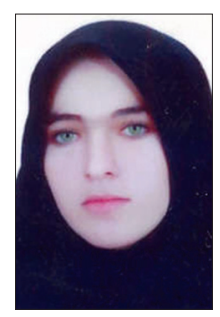

Ensiyeh Taheri was born in Iran in 1986. She received the Ph.D. degree from Isfahan University on Medical sciences in 2017.

Dr. Taheri is a member of Department of Environmental Health Engineering, School of Health, Isfahan University of Medical Sciences, and also student research committee, School of Health, Isfahan University of Medical Sciences, Isfahan Iran.

Email: e_taheri_83@yahoo.com

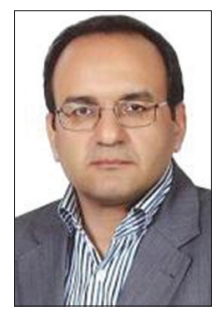

Mohammad Mehdi Amin was born in Iran in 1966. He received the Ph.D. degree from Isfahan University on Medical sciences in 2003.

Professor Amin is member of Department of Environmental Health Engineering, School of Health, and Environment Research Center, Research Institute for Primordial Prevention of Non-Communicable Disease, Isfahan University of Medical Sciences, Isfahan, Iran.

Email: amin@hlth.mui.ac.ir

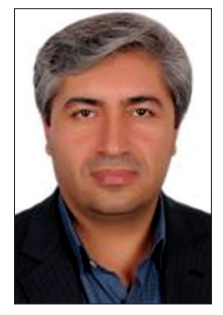

Hamidreza Pourzamani received the M.Sc. and Ph.D degree from Isfahan University on Medical sciences in 2004 and 2011, respectively.

He is member of Department of Environmental Health Engineering, School of Health, and Environment Research Center, Research Institute for Primordial Prevention of Non-Communicable Disease, Isfahan University of Medical Sciences, Isfahan, Iran

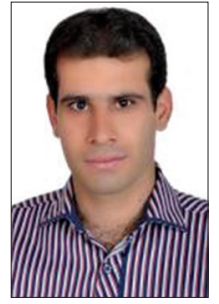

Ali Fatehizadeh was born in Iran in 1984. He received the M.Sc. degree from Kerman University on Medical sciences in 2010 and Ph.D. degree from Isfahan University on Medical sciences in 2015.

Dr. Fatehizadeh is member of Department of Environmental Health Engineering, School of Health, and Environment Research Center, Research Institute for Primordial Prevention of Non-Communicable Disease, Isfahan University of Medical Sciences, Isfahan, Iran

Email: Fatehizadeh@gmail.com, A.Fatehizadeh@hlth.mui.ac.ir

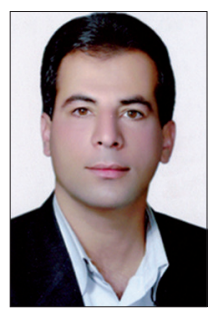

Mohammad Ghasemian received the Ph.D degree from Isfahan University on Medical sciences in 2017.

He is member of Environment Research Center, Research Institute for Primordial Prevention of Non-Communicable Disease, Isfahan University of Medical Sciences, Isfahan, Iran

Email: Ghasemian2005@gmail.com

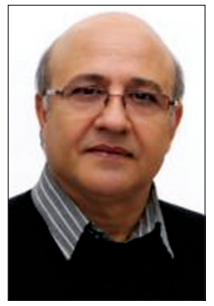

Bijan Bina received the M.Sc. and Ph.D degree from University of Newcastle upon Tyne, UK, in 1987 and 1991, respectively. Professor Bina is member of Department of Environmental Health Engineering, School of Health, Isfahan University of Medical Sciences, Isfahan, Iran

Email: bbina123@yahoo.com, Bina@hlth.mui.ac.ir

Email: pourzamani@hlth.mui.ac.ir 